\title{
TERCEIRIZAÇÃO NA ADMINISTRAÇÃO PÚBLICA: CONSIDERAÇÕES PARA O ESTUDO DO CASO DA UNIVERSIDADE FEDERAL FLUMINENSE
}

\author{
Thaís Castro Koch ${ }^{1}$ \\ Orcid: https://orcid.org/0000-0002-2006-375X \\ Hernán Armando Mamani \\ Orcid: https://orcid.org/0000-0002-4698-0601
}

Recebido em: 17 mar. 2021

Publicado em: 28 abr. 2021

\section{RESUMO}

Este trabalho tem como objetivo principal, traçar vias analíticas que permitam interpretar o processo de terceirização da Universidade Federal Fluminense entre os anos de 1995 a 2019. A terceirização é uma forma de organização dos processos de trabalho, na qual as funções produtivas e administrativas utilizam total ou parcialmente mão de obra subcontratada. Além de constituir um elemento central do paradigma gerencial contemporâneo, que alcançara, também, o setor público no Brasil. Consideramos que a universidade pública, apesar de sua autonomia, permite-nos observar um fenômeno muito mais amplo: a definição dos processos de organização do trabalho a partir do alto escalão do Estado - distantes dos processos produtivos, da definição dos fins e da avaliação dos resultados, contribuindo assim para a ineficiência dos serviços. Nesse sentido, a terceirização de atividades promovidas nas universidades públicas teria escassa incidência sobre a qualidade de seus produtos, sobre a eficiência dos processos e sobre inovação na prestação de serviços.

PALAVRAS-CHAVE: Terceirização. Administração pública. Universidade pública.

\section{OUTSOURCING IN PUBLIC MANAGEMENT: CONSIDERATIONS FOR THE CASE STUDY OF UNIVERSIDADE FEDERAL FLUMINENSE}

\begin{abstract}
This work has as its main objective to outline analytical paths that allow interpreting the process of outsourcing at the Universidade Federal Fluminense between the years 1995 to 2019. Outsourcing is a form of organisation of work processes, in which productive and administrative functions make full or partial use of subcontracted labour. In addition

\footnotetext{
${ }^{1}$ Administradora no Instituto de Ciências da Sociedade e Desenvolvimento Regional da Universidade Federal Fluminense. Mestre em Desenvolvimento Regional, Ambiente e Políticas Públicas (PPGDAP), da Universidade Federal Fluminense (UFF).

${ }^{2}$ Doutor em Planejamento Urbano e Regional pelo Instituto de Pesquisa e Planejamento Urbano e Regional (2004). Atualmente é professor associado da Universidade Federal Fluminense.
} 
to being a central element of the contemporary managerial paradigm, which had also reached the public sector in Brazil. We consider that the public university, despite its autonomy, allows us to observe an overly broad phenomenon: the definition of the processes of work organisation from the top echelons of the State - distant from the productive processes, from the definition of ends and the evaluation of results, contributing to inefficient services. In this sense, the outsourcing of activities promoted in public universities has little impact on the quality of their products, on process efficiency and on innovation in service provision.

KEYWORDS: Outsourcing. Public Administration. Public University.

\section{INTRODUÇÃO}

Este trabalho trata da terceirização na administração pública a partir da experiência da Universidade Federal Fluminense (UFF) entre os anos de 1995 a 2019. Interessa-nos esboçar vias analíticas que permitam compreender como ocorre e se gere o processo de terceirização nas universidades públicas, considerando sua relação com a organização do trabalho e os processos produtivos. Esta abordagem se justifica por serem escassos os trabalhos que tratam da terceirização nas universidades públicas e, porque a terceirização tem se apresentado como uma forma de trabalho em expansão nas instituições públicas de ensino superior, como veremos.

De fato, o número de terceirizados contratados pela UFF no ano de 2006, chegou a 13,58\%, em 2008 esse número alcançou 14,51\% dos trabalhadores, já em 2018, esse quantitativo atingiu $21,26 \%$ dos trabalhadores da universidade ${ }^{3}$. Por outro lado, as poucas pesquisas sobre a terceirização do trabalho no serviço púbico, partem do suposto de que a terceirização conduz, necessariamente, à precarização do trabalho e, que está por sua vez, é provocada por uma contínua "contrarreforma neoliberal” (DRUCK, DUTRA E SILVA, 2019) ${ }^{4}$, cujas origens remonta a modernização do Estado brasileiro promovida nos anos de 1990. Não questionamos este viés, contudo, ele não nos oferece elementos suficientes para tratar da terceirização na perspectiva que adotamos.

Ao tratar da terceirização na esfera pública, é fundamental fazer referência à Reforma do Aparelho do Estado, ocorrida a partir de 1995, durante o primeiro mandato do governo de Fernando Henrique Cardoso; dado que, naquele período, a subcontratação

\footnotetext{
${ }^{3}$ Dados obtidos por meio dos Relatórios de Gestão da UFF dos anos de 2006 a 2019.

${ }^{4}$ Esse trabalho recente realizado por Druck, Dutra e Silva (2019), discute a aprovação da reforma trabalhista ocorrida em 2017 no governo de Michel Temer, analisando-a como a "contrarreforma neoliberal", que tem a "precarização como regra".
} 
de trabalhadores ganhou visibilidade e escopo. De fato, a Reforma Gerencial proposta por Bresser Pereira ${ }^{5}$, era apresentada por ele, como uma forma de escapar da disjuntiva do debate entre os defensores de um Estado mínimo e os adeptos de uma maior presença do Estado. Bresser justificou sua proposta afirmando não se tratar de uma questão de tamanho, senão de sua eficiência, sendo preciso substituir uma administração burocrática por uma administração gerencial (BRESSER, 1996, p.5). Semelhante ao que ocorreu nas empresas privadas, mediante a focalização nas atividades-fim ${ }^{6}$, a Reforma do Estado afirmava buscar eficiência no cumprimento dos fins públicos. Justificava a introdução da subcontratação e da organização em redes no interior do Estado, como que obedecendo a uma modernização gerencial.

O modelo de gestão sugerido aproxima-se do "paradigma da especialização flexível $^{7}$, proposto por Piore e Sabel, para descrever as experiências gerenciais de sucesso japonesas, ou da terceira Itália na década de 1980, as quais pareciam constituir um novo e exitoso regime produtivo. Acreditamos que retomar a terceirização desta perspectiva, fornecera elementos para analisar a organização do trabalho nas universidades públicas. Apesar de sua autonomia quanto à dimensão cientifica e acadêmica e, de dispor de orçamento próprio, essas instituições tem escassa liberdade de ação quando se trata de provisão de vagas e organização dos processos de trabalho.

O texto apresenta, inicialmente, o debate sobre a terceirização no Brasil, chamando à atenção para o fato de ser inteiramente voltado às empresas privadas. Além disso, mostra como o tema se relaciona à discussão sobre a reestruturação produtiva, os novos paradigmas produtivos e se esforça a compreender como este debate se entrelaça com a reflexão sobre a Reforma do Estado e o lugar que a universidade ocupa nessa proposta. Também, buscaremos compreender como ocorreu a terceirização na UFF, através do acompanhamento das leis que, permitiram pouco a pouco a terceirização no serviço público. E, por último, efetuaremos a caracterização da UFF, sua formação, organização e os desafios que encontramos. Ambos dificultam uma interpretação

\footnotetext{
${ }^{5}$ Destacamos os pensamentos de Luis Carlos Bresser Pereira, considerando que, além de ter sido Ministro da Administração Federal e Reforma do Estado responsável pela tentativa de implementação do modelo gerencial na administração pública brasileira, ele produziu, em sua defesa, uma obra consistente e bem fundamentada.

${ }^{6}$ Atividades consideradas essenciais ou estratégicas (BRASIL, Decreto n ${ }^{\circ}$ 9.507/18).

7 Modelo de organização da produção, em que esforços coletivos, compreendidos por trabalhadores especializados, se apresentam flexíveis frente às transformações do mercado, como o caso dos Distritos Industriais.
} 
demiúrgica do Estado.

\section{O DEBATE SOBRE A TERCEIRIZAÇÃO}

Entendemos a terceirização como uma forma de organização dos processos de trabalho, em que as funções produtivas e administrativas utilizam total ou parcialmente de mão de obra subcontratada. Tal termo caracteriza "todo processo de contratação de trabalhadores por empresa interposta. É uma relação na qual o trabalho é realizado para uma empresa, mas contratado de maneira imediata por outra" (MARCELINO, 2007, p. 57), sendo utilizada tanto no setor privado quanto no setor público. Definida assim, a terceirização no Brasil constitui uma prática antiga que remonta ao trabalho rural, às atividades conhecidas como "gato" desenvolvidas na agricultura e também na contratação em áreas urbanas, durante a industrialização (DRUCK, SENA, PINTO E ARAÚJO, 2018, p. 114) ${ }^{8}$. A terceirização tornou-se objeto de debate em ciências sociais a partir da década de 1990, por ocasião das reformas introduzidas na legislação trabalhista no início de aquela década, bem como, a chamada, reestruturação produtiva ${ }^{9}$, que a partir de então, mudou a organização econômica do país e do mundo.

A terceirização é um dos vários aspectos da organização produtiva, que a partir dos anos 1970 e 1980, se apresentou como alternativa para superar o modelo de organização produtivo fordista, burocrático ou rígido, tal como apontado por Piore e Sabel (1989). A produção em série para um mercado de massas, realizada com trabalhadores assalariados, especializados e dispostos, ao longo de uma esteira móbil, tinha se tornado, a partir do final do século XIX, o paradigma produtivo dominante, e sua crise, evidenciada ao longo da década de 1970, abriu a concorrência na busca de um novo

\footnotetext{
${ }^{8}$ Além disso, as autoras destacam a primeira experiência do Estado brasileiro com a terceirização ainda no século XIX. A experiência que se poderia denominar como a primeira de uma terceirização realizada pelo Estado brasileiro data do século XIX, mais precisamente de 1852, quando são tomadas iniciativas para substituir o trabalho escravo pelo trabalho dos migrantes pobres europeus. Um dos pioneiros foi o grande fazendeiro e senador Nicolau Pereira de Campos Vergueiro, que, após ter importado por sua própria conta mais de trezentas famílias da Suíça e da Alemanha, resolveu se "associar" ao governo de São Paulo para trazer 1.500 colonos. Para isso, formou a empresa Vergueiro \& Cia., que se tornou uma agenciadora de mão de obra estrangeira para as grandes plantações, subcontratada pelo governo que passou a financiar a vinda desses trabalhadores (DRUCK, SENA, PINTO E ARAÚJO, 2018, p. 114).

${ }^{9}$ A saturação do fordismo e sua visível rigidez frente à crise fiscal e a necessidade de adaptação por parte das corporações, ocasionou mudanças significativas no mundo do trabalho, configurando a reestruturação produtiva. Tal processo foi pautado pela flexibilização, introdução de novos padrões de trabalho, inovações tecnológicas e empresariais. (HARVEY, 1989, p. 135-162).
} 
paradigma $^{10}$. Os autores não afirmam, assim, que a subcontratação de trabalhadores e de empresas para a realização de atividades produtivas fosse uma atividade desconhecida da produção moderna e nas economias centrais, mas, era tomada como uma prática periférica característica de atividades particulares e retrasadas da economia; senão que na procura por soluções para a crise, as experiências positivas serviam de modelo para a formação de um novo paradigma. A via japonesa, a experiência da Terceira Itália ${ }^{11}$ e a dos grandes distritos industriais contemporâneos foram analisados e modernizados.

O “paradigma da especialização flexível” proposto por Piore e Sabel,

...é uma estratégia de inovação permanente, um viés para se adaptar à mudança perpétua em vez de tentar controlá-la. Esta estratégia baseiase na utilização de equipamentos flexíveis e polivalentes, no emprego de trabalhadores qualificados e na criação, por meios políticos, de uma comunidade industrial capaz de eliminar todas as formas de concorrência que não promove a inovação (PIORE E SABEL, 1989, p. $35)$.

Para os críticos deste novo "regime produtivo", as inovações propostas não passariam de modos de organização da produção, focada na produtividade e na adequação da produção à lógica do mercado. Mas é a ênfase na concorrência baseada na inovação que destaca a experiência japonesa e, mais precisamente, do regime produtivo adotado pela Toyota, que se provou capaz de inovar e se ajustar a mercados saturados, mediante uma organização do trabalho enxuta, na qual a produção era completamente ajustada à demanda, mediante o ajustamento dos processos produtivos, tanto no que se refere ao

\footnotetext{
10 "Incapacidade da estrutura institucional de assumir a difusão da tecnologia de produção em massa" (PIORE E SABEL, 1989, p. 214-215).

${ }^{11}$ Após a crise dos anos 50, com a instabilidade evidenciada pela decadência da produção em massa, os setores considerados dominados passaram a trabalhar de maneira "federalizada" constituindo redes, as quais se localizavam em antigas áreas industriais Italianas a partir da década de 70. Tais medidas se mostraram satisfatórias, sendo a experiência artesanal considerada um sistema de produção viável. A subcontratação fez parte dessa experiência, na medida em que pequenas oficinas, muitas desses familiares, mitigavam os riscos das empresas por executarem atividades de forma indireta. (PIORE E SABEL, 1989, p.273-274).
} 
fornecimento (Just-in-time ${ }^{12}$ e Just-in-case $\left.{ }^{13}\right)$, a linha de montagem $\left(\right.$ Kan-ban $\left.^{14}\right)$ e ao aumento da qualidade promovida internamente pelos círculos de Controle de Qualidade (CQQs) (ANTUNES, 2002, p. 34) ${ }^{15}$.

Mas o singular a respeito da subcontratação de empresas é a maneira em que se dá a relação entre estas, como parceiras capazes de contribuir para a inovação. Certamente, os benefícios desta parceria não se distribuem por igual entre empresas e trabalhadores. Nas montadoras e nos principais fornecedores, concentrar-se-ia o trabalho masculino, qualificado e bem pago, enquanto na base da pirâmide de subcontratações, localizar-se-ia o trabalho feminino, mal remunerado e pouco qualificado, o trabalho a domicílio e um sem-fim de relações de trabalho e produção pouco estáveis (HARVEY, 2008, p. 146). Ocorre que esta dimensão do toyotismo é omitida ou destacada segundo a posição dos autores.

Nossa ênfase no uso modelar da experiência japonesa procura destacar que o empreendimento de Piore e Sabel (1984), visa propor alternativas gerenciais e empresarias, sugere modelos gerenciais capazes de promover a inovação a baixo custo e, ao mesmo tempo, buscam alternativas para a estagnação econômica. Não há qualquer reflexão sobre as funções públicas, na medida em que, para Piore e Sabel (1984) a organização keynesiana dos Estados Nacionais consiste num dos fatores de rigidez econômica, dado que, se tornaram incapazes de regular o subconsumo e de garantir a proteção social. Paralelamente, o papel internacional fragilizava-se devido ao aumento da concorrência econômica entre nações e o enfraquecimento das instituições que regularam

\footnotetext{
${ }^{12} \mathrm{O}$ método Just-in-time tem como objetivo dar uma resposta às necessidades e imprevistos, tendo como foco a redução de produtos em processo. É considerado o segundo pilar do espírito Toyota, extraído da indústria têxtil, tal princípio muniu as máquinas de tear com dispositivos que permitiam a parada automática das máquinas em caso de anomalias, evitando desperdícios (CORIAT, 1994, p. 52).

${ }^{13}$ A gestão por meio do Just-in-case objetiva otimizar a rentabilidade dos meios de produção utilizando o gerenciamento de sistemas de controle e supervisão de recursos de forma externa ao processo produtivo, antecipando demandas futuras (ANTUNES JR, KLIEMANN NETO, FENSTERSEIFER, 1989, p. 51).

${ }^{14} \mathrm{O}$ método Kan-ban surge como uma técnica que viabiliza o método Just-in-time. A técnica é criada no momento em que a Toyota escolhe enfrentar o aumento da demanda sem aumentar seu pessoal. Tal técnica permite o controle dos processos por meio de comunicação interna, conforme a necessidade ações durante o processo produtivo, através da utilização de cartões que sinalizam partes da produção, formando um "fluxo de informação invertido que vai de jusante à montante da cadeia produtiva, e onde cada posto posterior emite uma instrução destinada ao posto que lhe é imediatamente anterior" (CORIAT, 1994, p. 5657).

${ }^{15}$ Há elementos históricos particulares - sindicalismo de empresa - depois da derrota do movimento operário nos anos 50 .
} 
a expansão econômica do pós-guerra $\left(\mathrm{GATT}^{16}, \mathrm{FMI}^{17}\right.$ e $\left.\mathrm{BM}^{18}\right)$. Em tais circunstâncias, uma nova regulação econômica poderia ser realizada, tanto pela adoção do paradigma da especialização flexível no nível das empresas, quanto pela adoção de um Keynesianismo internacional $^{19}$. Mas, ao entrar na dimensão geopolítica desta modelagem, afastamo-nos da problemática da terceirização.

O debate sobre a terceirização envolve vários aspectos não idênticos. $\mathrm{O}$ primeiro, de que tratamos até aqui, envolve a relação entre firmas - parcerias - na promoção da inovação e da flexibilidade para ajustar-se às flutuações dos mercados mutáveis, associados aos ganhos advindos da focalização em nichos produtivos. O segundo relaciona-se à subcontratação de mão de obra tomada apenas como uma estratégia de flexibilização/precarização do trabalho (DRUCK, SENA, PINTO E ARAÚJO, 2018, p. 114-115). Entre ambas as visões, a pesquisa empírica tem demonstrado que em grande número de casos, a terceirização, muito além dos modelos preconizados, começou como um modismo malsucedido, do qual, tendem a predominar, apenas, a terceirização de mão de obra, sem contar com os elementos virtuosos da relação entre firmas. Assim, abre-se mão da subcontratação direta, sem inovação, como mero corte de custos. Tratar-se-ia, como caracterizado por Castro (1993), de uma “japanização de ocasião".

\section{TERCEIRIZAÇÃ̃ NA ADMINISTRAÇÃo PÚBLICA}

Se a problemática da terceirização envolve, essencialmente, o desempenho das empresas, a qualidade do trabalho e das relações de trabalho ofertadas, são poucos os casos em que se trata da terceirização no setor público. A terceirização tem sido uma prática recorrente na administração pública desde o decreto Lei $n^{\circ}$ 200/1967, contudo, diferentemente do que ocorre no setor privado, a administração pública possui regras e procedimentos específicos a serem seguidos, como a exigência de licitação e contratos, e

\footnotetext{
${ }^{16}$ General Agreement on Tariffs and Trade (Acordo Geral de Tarifas e Comércio).

${ }^{17}$ Fundo Monetário Internacional.

${ }^{18}$ Banco Mundial.

${ }^{19} \mathrm{Na}$ qual as instituições internacionais facilitassem o equilíbrio entre nações com mercados de consumo saturados e os países menos desenvolvidos capazes de dar vasão ao subconsumo, com tal estímulo seriam capazes de expandir com rapidez suficiente para fornecer a margem de crescimento necessária para todo o sistema (PIORE E SABEL, 1984).
} 
a aplicação de concurso público para seleção de servidores efetivos. Tais fatos corroboram para uma dimensão sui generis da questão da terceirização no setor público.

E o debate permanece enviesado pela perspectiva da precarização do trabalho, sem abordar outras dimensões importantes ao pensar a organização, os contratos e os processos de trabalho (que na modelagem de empresas explicam-se pelos resultados econômicos). A exceção, neste sentido, cabe a Bresser Pereira (1996) que como ministro de Reforma de Estado, produziu uma reflexão consistente - embora ampla e não experimentada - sobre o tema de forma simultânea à implementação da Reforma do Estado $^{20}$.

Para ele, o problema da modernização ${ }^{21}$ do Estado não se exprime adequadamente na oposição ente neoliberalismo X estatismo ou entre Estado Mínimo ou Estado Máximo. O problema não é o tamanho, senão a eficiência; é a falta de eficiência dos Estados ocidentais, após décadas de desenvolvimento no Pós-guerra ${ }^{22}$. Num contexto de globalização (em virtude dos públicos) e findas regulações de mercado globais, as formas de regulação econômica e social dos Estados Nacionais, exitosas por décadas, tornam-se obsoletas. Desta forma, os Estados revelam a "incapacidade de reconhecer os fatos novos" (BRESSER, 1996), se imobilizam e entram em crise fiscal.

A crise do Estado implicou na necessidade de reformá-lo e reconstruílo; a globalização tornou imperativa a tarefa de redefinir suas funções. Antes da integração mundial dos mercados e dos sistemas produtivos, os Estados podiam ter como um de seus objetivos fundamentais proteger as respectivas economias da competição internacional. Depois da globalização, as possibilidades do Estado de continuar a exercer esse papel diminuíram muito. Seu novo papel é o de facilitar para que a economia nacional se torne internacionalmente competitiva (BRESSER, 1996, p.1).

Para este autor, os fins econômicos do Estado, numa situação de concorrência global, devem oferecer mecanismos capazes de transformar a economia nacional internacionalmente competitiva. Mas, a organização burocrática do Estado - conformada no Brasil a partir dos anos 30 - deve ser substituída por uma "administração gerencial", conforme destaca o autor:

\footnotetext{
${ }^{20}$ Emenda Constitucional nº19/1998.

21 Tomamos como modernização a atualização técnica e administrativa da empresa estatal.

22 “.... as distorções de qualquer sistema de administração estatal são inevitáveis à medida que transcorre o tempo". (BRESSER, 1996).
} 


\begin{abstract}
As empresas estatais, que inicialmente se revelaram um poderoso mecanismo de realização de poupança forçada, na medida em que realizam lucros monopolistas e os investiam, foram aos poucos vendo esse papel se esgotar, ao mesmo tempo que sua operação se demonstrava ineficiente ao adotar padrões burocráticos de administração. Na realização das atividades exclusivas de Estado e principalmente no oferecimento dos serviços sociais de educação e saúde, a administração pública burocrática, que se revelara efetiva em combater a corrupção e o nepotismo no pequeno Estado Liberal, demonstrava agora ser ineficiente e incapaz de atender com qualidade as demandas dos cidadãos-clientes no grande Estado Social do século vinte, tornando necessária sua substituição por uma administração pública gerencial (BRESSER, 1998, p.55).
\end{abstract}

Esta proposta explicar-se-ia por esse tipo burocrático de administração ser incapaz de se relacionar diretamente com os mercados e de dar conta das demandas regulatórias que as atividades econômicas precisam numa era de globalização. Igualmente, carece de uma estrutura interna e um dinamismo que lhe permita estimular a eficiência, a inovação e a competitividade, garantindo eficiência no atendimento ao "cidadão-cliente", ou seja, operar como um prestador de serviços púbicos. Para isto, deve mudar o modo em que se define o papel do Estado, atuando "como regulador e facilitador ou financiador a fundo perdido desse desenvolvimento" (BRESSER, 1998, p.98).

A promoção desse Estado Social-Liberal ${ }^{23}$ visava o aumento da governança e da governabilidade mediante a delimitação das funções do Estado e sua redução do grau de interferência sobre o econômico e o social. O autor defendia que:

A capacidade política de governar ou governabilidade deriva da relação de legitimidade do Estado e do seu governo com a sociedade, enquanto que governança é a capacidade financeira e administrativa em sentido amplo de uma organização de implementar suas políticas. (Idem, p. 82$83)$.

O aumento da governabilidade corresponderia a incrementar a capacidade de garantir "uma melhor intermediação de interesses por parte das instituições políticas e de tornar mais legítimos e democráticos os governos", enquanto o aumento da governança ocorreria pelo "ajuste fiscal que de devolveria autonomia financeira ao Estado" (Idem, p. ${ }^{23} \mathrm{Na}$ medida em que incorpora a busca da competitividade internacional como condição do
desenvolvimento e a atualização das prestações sociais. 
60). A condição de ambas seriam, para Bresser Pereira (1998), a delimitação das funções do Estado e redução de seu grau de interferência.

O Estado, segundo a definição weberiana à qual o autor adere, é uma empresa de natureza particular, visto que monopoliza a lei e a violência num determinado território, garantindo a representação externa do país e, no tocante a ordem e a previsibilidade dos negócios (juízes, fiscais). Mas há:

...outras atividades que lhe são exclusivas correspondentes (...). Em essência são as atividades de formular políticas na área econômica e social e, em seguida, de realizar transferências para a educação, a saúde, a assistência social, a previdência social, a garantia de uma renda mínima, o seguro desemprego, a defesa do meio ambiente, a proteção do patrimônio cultural, o estímulo às artes (BRESSER, 1998, p.64).

De fato, as atividades enumeradas não correspondem às exclusivas do Estado, contudo, dado o volume de recursos que requerem sua produção ${ }^{24}$, o seu caráter estratégico torna inviável outras formas de produção e oferta destes serviços.

A “focalização" promovida pela delimitação de funções implica que as atividades econômicas, bem como muitas atividades sociais, não precisam ser desempenhadas pelo Estado, desde que este atribua, politicamente, o fim e o controle dos resultados. Nesse sentido, seria adequado propor a privatização de um conjunto de atividades econômicas prestadas pelo Estado, e a atribuição de uma série de serviços sociais a associações privadas já existentes, numa concessão de serviços denominada "publicização". Esta forma estatal de promoção de redes de empresas e de parcerias, não guarda para terceirização um lugar virtuoso. Como nas empresas privadas, terceirizam-se, em princípio, atividades não essenciais.

Em suma, a administração pública gerencial:

a) orienta-se para o "cidadão-usuário ou cidadão-cliente"; b) enfatiza o " controle dos resultados através dos contratos de gestão (...) ao invés de controle dos procedimentos"; c) busca "fortalecer a autonomia da burocracia estatal, organizada em carreiras ou .corpos de Estado (...) valorizando do seu trabalho técnico e político de participar (...) na formulação e gestão das políticas públicas; d) separação entre as secretarias formuladoras de políticas públicas, de caráter centralizado, e as unidades descentralizadas, executoras

\footnotetext{
24 O principal argumento econômico que as justifica é o de que estas são atividades que envolvem externalidades positivas importantes, não sendo, portanto, devidamente remuneradas pelo mercado. A arte e a ciência são claramente casos desse tipo.
} 
dessas mesmas políticas; e) distinção de dois tipos de unidades descentralizadas: as agências executivas, que realizam atividades exclusivas de Estado, por definição monopolistas, e os serviços sociais e científicos de caráter competitivo, em que o poder de Estado não está envolvido; f) transferência para o setor público nãoestatal dos serviços sociais e científicos competitivos; g) adoção cumulativa, para controlar as unidades descentralizadas, dos mecanismos (1) de controle social direto, (2) do contrato de gestão em que os indicadores de desempenho sejam claramente definidos e os resultados medidos, e (3) da formação de quase-mercados em que ocorre a competição administrada; h) terceirização das atividades auxiliares ou de apoio, que passam a ser licitadas competitivamente no Mercado privatização, terceirização e publicização (BRESSER, 1998. p. 80-81).

Dado que tratamos aqui das transformações introduzidas na universidade pública, e, dentro delas, a terceirização, é importante frisar que Bresser Pereira considera que, apesar de não serem funções exclusivas do Estado,

(...) o seu financiamento em grandes proporções é uma atividade exclusiva do Estado (...) sua execução definitivamente não o é. Pelo contrário, estas são atividades competitivas, que podem ser controladas não apenas através da administração pública gerencial, mas também e principalmente através do controle social e da constituição de quasemercados $^{25}$ (Idem, p.66).

Na medida em que a atividade não pode gerar todas as suas receitas das vendas de seus produtos e que dependem, fortemente, do financiamento público, sua gestão pode muito bem ser entregue a organizações públicas não-estatais. Isto implica alterar, através da gestão gerencial; uma alternativa para a privatização ${ }^{26}$.

A gestão por "quase mercados" citada por Bresser Pereira, não é descrita por ele. Nesse contexto, a administração gerencial previa a transferência de certas atividades para a esfera privada, por meio da definição de atividades principais e atividades auxiliares ou de apoio. Sob esta lógica, as atividades de apoio ou auxiliares na administração pública

\footnotetext{
${ }^{25}$ O autor não define esta noção. Segundo Souza e Oliveira (2003) a especificidade da oferta de serviços sociais, leva a conceber como necessárias formas de organização "intermediárias entre as estruturas estatais, alheias à lógica de mercado, e o mercado concorrencial típico" capazes de estimular a competitividade e a inovação nessas atividades.

${ }^{26}$ As Universidades Públicas brasileiras, conforme a proposta da Reforma Administrativa, se enquadram nas atividades não-exclusivas, sendo o seu financiamento garantido pelo Estado, mas sua execução estaria aberta à concorrência, implicando na publicização das atividades, ou seja, na transferência para o setor público não-estatal. Conforme salienta Bresser Pereira, o objetivo da Reforma Administrativa seria transitar do modelo de administração pública burocrática para a gerencial, "aproveitando das conquistas da primeira", ao mesmo tempo em que são feitas as alterações necessárias, o autor sugere a combinação entre o burocrático e o gerencial, conforme o setor e a carência por eficiência (BRESSER, 1996, p. 24).
} 
passaram a ser submetidas a licitação pública e a contratos com terceiros. Em poucas palavras, a terceirização, no caso da reforma do Estado, constitui um elemento da administração gerencial que não difere, em essência, dos critérios da iniciativa privada tratado aqui como paradigma da especialização flexível. Seria possível pensar, então, nesta reforma como um aggiornamento da organização estatal segundo os critérios das empresas contemporâneas. A focalização e a flexibilidade são elementos centrais deste 'modelo'. Contudo, trata-se, no caso em questão, de uma modelização com escassa experimentação ${ }^{27}$. Até que ponto os elementos da administração gerencial, propostos por Bresser Pereira, são exitosos de fato? Qual seria o grau de eficácia e o alcance das mudanças? Como se definem os fins e os critérios de avaliação dos empreendimentos púbicos?

\section{PARA ALÉM DO MODELO: CONTEXTO EMPÍRICO}

Os argumentos de Bresser Pereira são fortes quanto à necessidade de ajustar as formas de organizar o Estado aos meios e aos fins. Segundo ele, o 'modelo administrativo burocrático' (racional-legal) em que se pauta o Estado brasileiro, desde os anos 30, tornou-se autoritário e ineficiente ao longo do tempo e, portanto, inadequado para alcançar seus objetivos constitucionais. Mas este argumento quando retomado da perspectiva da terceirização, fragiliza-se. Não resulta muito claro que o Brasil tenha adotado qualquer modelo administrativo preciso, estável, constante e homogêneo. E, por outro lado, o seu referencial, quanto às formas contemporâneas de administração pública bem permite encontrar paralelos consistentes com o paradigma da especialização flexível, modelado a partir de empresas e para empresas. Entretanto, não é claro e nem provado como este o modelo se sustenta empiricamente e, muito menos como o faz na própria experiência brasileira.

Certamente, a administração pública organiza-se, a partir dos anos 30, segundo um critério racional-legal, e as empresas públicas desempenharam um papel central no desenvolvimento do capitalismo industrial brasileiro. Porém, uma análise mais detalhada

\footnotetext{
${ }^{27}$ Seu modelo baseia-se em exemplos de alguns países centrais e nas recomendações do Fundo Monetário Internacional e Banco Mundial.
} 
dos processos de contratação e formação de empresas e empreendimento prova-se menos modelar e mais aleatório. Buscaremos apontar esta possibilidade: 1) através de um acompanhamento legal da terceirização do serviço público 2) e da caracterização da UFF, sua formação, sua organização e os desafios que encontramos.

\subsection{A terceirização no serviço público - evolução histórica-normativa}

A Revolução ocorrida nos anos 1930 culminou em mudanças significativas no país, sendo considerado o marco inicial da Segunda República no Brasil. No que diz respeito ao funcionalismo público, este ganhou maior escopo em razão de medidas propostas pelo governo de Getúlio Vargas, como a criação do Conselho Federal do Serviço Público (CFSPC) em 28 de outubro de $1936^{28}$. Tal órgão visava, dentre outras atividades, a realização de estudos voltados para a organização dos serviços públicos e para a elaboração de concursos públicos (Diretório Brasil de Arquivos).

Nessa perspectiva, a Constituição de 1937 ressaltou a necessidade de um departamento de administração capaz de gerir de forma responsável e racionalizada, o serviço público no país, constituindo, assim, o Departamento Administrativo do Serviço Público (DASP), criado pelo decreto no 579 de 30 de julho de 1938, em suplantação do CFSPC, cujas funções foram transferidas ao DASP. Além de outras atribuições, competia ao DASP a fiscalização orçamentária e a seleção de candidatos para os cargos públicos ${ }^{29}$.

Em seguida, o DASP desempenhou importante papel no processo de consolidação de políticas governamentais implementadas. Em 1939, o decreto $n^{\circ} 1713$ dispôs sobre o estatuto dos funcionários públicos ${ }^{30}$ civis da união, trazendo questões importantes relacionadas à carreira, ao vencimento dos cargos públicos ${ }^{31}$ fixados em lei, aos tipos de provimentos, à vacância dos cargos, nomeações, posse, à realização de concursos; dentre outros pontos.

\footnotetext{
${ }^{28}$ Lei $n^{\circ} 284 / 1936$ - Reajusta os quadros e os vencimentos do funcionalismo público civil da União e estabelece diversas providencias.

${ }^{29}$ Exceto os cargos das Secretarias da Câmara dos Deputados e do Conselho Federal e os do magistério e da magistratura.

${ }^{30}$ Pessoa legalmente investida em cargo público - Decreto $n^{\circ} 1.713 / 39$.

${ }^{31}$ São os criados por lei, em número certo, com denominação própria e pagos pelos cofres da União Decreto $\mathrm{n}^{\circ} 1.713 / 39$.
} 
Na administração pública brasileira, o Decreto-Lei no 200/1967 estabeleceu diretrizes quanto à descentralização das atividades, por meio de contratação ou execução indireta de serviços pelo setor privado, com a prerrogativa de maior concentração nas atividades de planejamento, supervisão e controle ${ }^{32}$ :

$\S 7^{\circ}$ Para melhor desincumbir-se das tarefas de planejamento, coordenação, supervisão e controle e com o objetivo de impedir o crescimento desmesurado da máquina administrativa, a Administração procurará desobrigar-se da realização material de tarefas executivas, recorrendo, sempre que possível, à execução indireta, mediante contrato, desde que exista, na área, iniciativa privada suficientemente desenvolvida e capacitada a desempenhar os encargos de execução.

Alguns anos depois, a lei $\mathrm{n}^{\mathrm{o}} 5.645 / 70$ - que "estabeleceu diretrizes para a classificação de cargos do Serviço Civil da União e das autarquias federais, e deu outras providências", complementou o Decreto-lei de 1967, definindo os serviços que poderiam ser contratados de forma indireta: "atividades relacionadas com transporte, conservação, custódia, operação de elevadores, limpeza e outras assemelhadas serão, de preferência, objeto de execução indireta, mediante contrato" (Art. $3^{\circ}$, Parágrafo único $)^{33}$.

Em 1974, a lei nº 6.019 dispôs sobre o trabalho temporário nas empresas urbanas $^{34}$, sem esclarecer no texto original, quais atividades poderiam ser subcontratadas, tratando mais das características das empresas que contratariam trabalhadores. Esta definição ocorre nove anos mais tarde, em 1983, pela lei no 7.102, que irá estipular a terceirização dos serviços de vigilância e transporte de valores.

Todavia, a constituição de 1988 foi um divisor de águas para a administração pública no Brasil, visto que, além de grandes alterações em toda conjuntura do país, foi a partir de sua promulgação, que o instituto do concurso público consolidou-se no Brasil, incluindo os Estados e os Municípios às regras de investiduras em cargos públicos e a

\footnotetext{
32 O decreto Lei $n^{\circ}$ 200/1967 organizou a administração federal em administração direta - se constitui dos serviços integrados na estrutura administrativa da Presidência da República e dos Ministérios - e administração indireta - entidades de personalidade jurídica própria como as autarquias, fundações, sociedade de economia mista e empresas públicas. Além disso, tal decreto-lei concretizou a possibilidade de a administração pública contratar serviços terceirizados para a execução de atividades consideradas de apoio, em razão de maior foco nas atividades essenciais e "impedir o crescimento desmesurado da máquina administrativa".

${ }^{33}$ Revogado pela Lei no 9.527 de 1997.

34 “Art. $4^{\circ}$ - Compreende-se como empresa de trabalho temporário a pessoa física ou jurídica urbana, cuja atividade consiste em colocar à disposição de outras empresas, temporariamente, trabalhadores, devidamente qualificados, por elas remunerados e assistidos" - Lei n 6.019 de 1974.
} 
incorporação dos princípios $^{35}$ inerentes à Administração Pública. Nessa lógica, a Constituição Federal de 1988 reafirmou a estabilidade dos funcionários públicos concursados, após um período de dois anos ${ }^{36}$ de estágio probatório.

A lei $n^{\circ} 8.112$, a qual passa a dispor sobre o Regime Jurídico dos servidores Públicos da União, das autarquias e das fundações públicas federais foi publicada no ano de 1990. Tal norma apresenta em suas minúcias as relações de trabalho estabelecidas entre os servidores federais e a administração pública, apresentando desde os requisitos para a investidura em cargo público, direitos, vantagens, deveres, proibições, penalidades, entre outros pontos. Nesse sentido, a União optou pelo regime estatutário tendo em vista que os servidores públicos são considerados "instrumentos de atuação do Estado" e necessitam de assumir responsabilidades e competências, não sendo, desse modo, compatíveis com o regime trabalhista (BANDEIRA DE MELO, 1996, p. 154-155).

Apesar desse importante marco, tal fato não foi suficiente para cessar a subcontratação de trabalhadores na administração pública brasileira. Pelo contrário, observa-se nos anos que seguiram, um esforço por normatizar as licitações e os contratos na administração pública. Segundo a lei de licitação ${ }^{37}$, tal mecanismo tem como objetivo assegurar a "isonomia, a proposta mais vantajosa para a administração e a promoção do desenvolvimento nacional sustentável", tendo em vista os princípios constitucionais básicos. No mesmo sentido, a lei no 8.987 de 1995 enunciou o regime de concessão e prestação de serviços públicos delegados - a terceirização - na administração pública.

Conforme destacamos, a subcontratação é um elemento constante na organização do Estado; com a Reforma do Estado, promovida pelo então Presidente Fernando Henrique Cardoso, a partir de 1995, a terceirização é contemplada como uma prática

\footnotetext{
${ }^{35}$ Legalidade, Impessoalidade, Moralidade, Publicidade e Eficiência. Sendo que, o princípio da eficiência foi acrescentado posteriormente por meio da Emenda Constitucional n ${ }^{\circ} 19$ de 04 de julho de 1998.

${ }^{36}$ A Emenda Constitucional no 19/98 alterou o art. 41 da Constituição Federal de 1988, fixando a estabilidade do servidor em 36 meses após avaliação de desempenho. Nessa medida, a administração pública tem entendido que o estágio probatório do servidor tenha se estendido de 24 meses para 36 meses, alterando a compreensão do que está disposto no art. n 20 da lei 8112/90.

${ }^{37}$ Lei no 8666 de 1993, posteriormente alterada pela lei no 12.349 de 2010.
} 
administrativa habitual, envolvendo atividades consideradas instrumentais, acessórias ou complementares - atividade-meio ${ }^{38}$ - distintas das atividades-fim ${ }^{39}$.

Esta política manteve-se relativamente estável até 2018 e 2019, quando os decretos $n^{\circ}$ 9.507/2018 revoga o decreto $n^{\circ}$ 2.271/1997, e, posteriormente, em 2019 o decreto $\mathrm{n}^{\circ} 10.183$ altera o decreto $\mathrm{n}^{\circ}$ 9.507, recém-publicado. Nesse sentido, tais alterações ampliaram as possibilidades de terceirização na administração pública. Sendo definidos como não terceirizáveis, atividades que:

Envolvam a tomada de decisão ou posicionamento institucional nas áreas de planejamento, coordenação, supervisão e controle (I), consideradas estratégicos (II); relacionados ao poder de polícia, de regulação, de outorga de serviços públicos e de aplicação de sanção; (III) e envolva categorias funcionais abrangidas pelo plano de cargos do órgão ou da entidade, exceto disposição legal em contrário ou quando se tratar de cargo extinto, total ou parcialmente, no âmbito do quadro geral de pessoa(IV) (Decreto $\mathrm{n}^{\circ}$ 9507/18).

As chances de terceirização abrem-se grandemente, dado que os fins do Estado se reduzem a planejamento, concessão e controle. Todas as outras atividades são passíveis, em tese, de privatização e terceirização. Muda não tanto o modelo gerencial, mas os critérios políticos ${ }^{40}$ que definem as atividades fins do Estado. Podemos afirmar que a terceirização tem sido um elemento constante da administração pública, ainda que os fins politicamente defendidos sejam mudados.

\subsection{Terceirização na UFF}

A formação da Universidade Federal Fluminense se deu como resposta a movimentos fluminenses que defendiam a necessidade de sediar as universidades em seus territórios. Como num sem-fim de outras universidades, o caso da criação da UFF, resultou

\footnotetext{
${ }^{38}$ Eram atividades passíveis de terceirização na administração conforme o Decreto no 2. 271/97: “Art. $1^{\circ}{ }_{-}$ $\S 1^{\circ}$ As atividades de conservação, limpeza, segurança, vigilância, transportes, informática, copeiragem, recepção, reprografia, telecomunicações e manutenção de prédios, equipamentos e instalações serão, de preferência, objeto de execução indireta".

${ }^{39}$ Eram atividades impossibilitadas de terceirizar na administração pública, conforme o Decreto $\mathrm{n}^{\circ} 2$. 271/97: “Art. $2^{\circ}-\S 2^{\circ}$ Não poderão ser objeto de execução indireta as atividades inerentes às categorias funcionais abrangidas pelo plano de cargos do órgão ou entidade, salvo expressa disposição legal em contrário ou quando se tratar de cargo extinto, total ou parcialmente, no âmbito do quadro geral de pessoal".

${ }^{40}$ Trataremos neste texto a expressão "critérios políticos" como jogos de interesses em relação as decisões e contextos.
} 
na reunião e federalização de uma série de institutos e escolas de nível superior, antes privados. Tal constituição se deu visando priorizar a formação de pesquisadores que pudessem contribuir para o desenvolvimento local e regional (Corte e Martins, 2010, p.9). Assim, do ponto de vista de sua estrutura funcional e administrativa, a UFF passou por várias experiências. O arcabouço de sua conformação atual está ancorado nos anos 1980 - de quando data seu regimento - e a estrutura funcional que articula técnicoadministrativos e docentes concursados com terceirizados no pós-constituinte. Por outro lado, se a terceirização tem se implementado nas últimas décadas - como mostraremos mais adiante -, não fica claro como a administração moderna e o incentivo à formação de "quase mercado" afetou a universidade.

\subsection{Organização}

A Universidade Federal Fluminense, cujo estatuto e regimento datam de 1983, possui uma estrutura organizacional verticalizada e organizada em Unidades Universitárias, Departamentos e Órgãos Suplementares que respondem diretamente à Administração Superior (Estatuto e Regimento Geral UFF, 1983), conforme observamos o organograma e a árvore hierárquica a seguir: 


\section{Figura 1: Organograma da UFF em 2019}

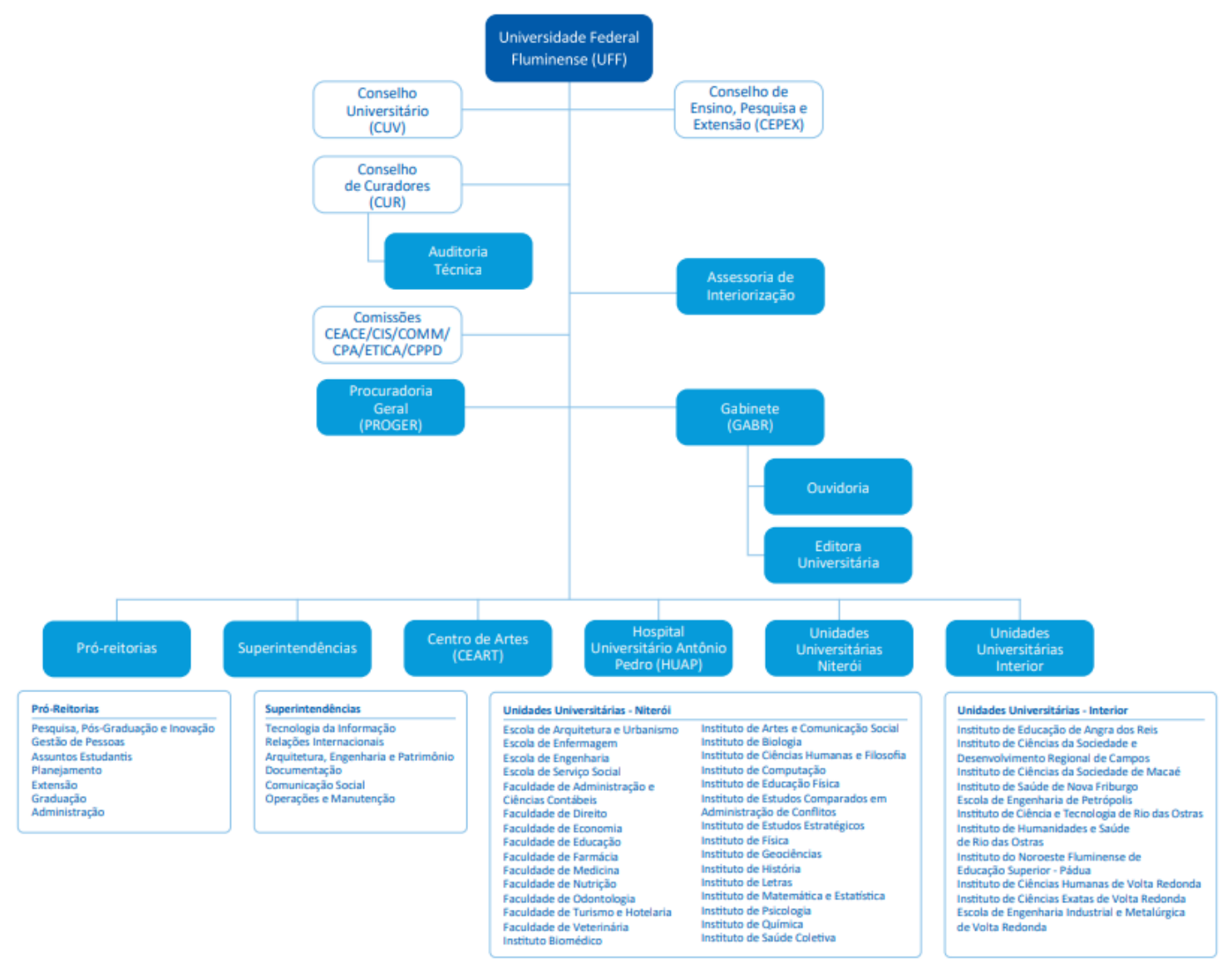

Fonte: UFF, (2019).

Pelo organograma dos órgãos da UFF, identificamos a complexidade da estrutura organizacional da universidade e o distanciamento ${ }^{41}$ estabelecido entre as instâncias superiores das atividades-fim. Afora isto, a centralização administrativa desta organização torna-se mais severa por se tratar de uma universidade multicampi ${ }^{42}$. Tal fato

\footnotetext{
${ }^{41} \mathrm{Na}$ contramão da gestão empresarial moderna.

${ }^{42}$ Criada em 1960 por meio da lei 3.958, inicialmente com o nome Universidade Federal do Estado do Rio de Janeiro (UFERJ) e posteriormente denominada Universidade Federal Fluminense (UFF), a UFF se expandiu ao longo do tempo, sendo uma universidade multicampi. Além da base em Niterói- RJ, a instituição possui unidades acadêmicas fora da sede, das quais oito estão no Estado do Rio de Janeiro e uma no Estado do Pará, são elas: Instituto de Educação de Angra dos Reis (Angra dos Reis/RJ); Instituto de Ciências da Sociedade e Desenvolvimento Regional (Campos dos Goytacazes/RJ); Instituto de Ciências da Sociedade (Macaé/RJ); Instituto de Saúde de Nova Friburgo (Nova Friburgo/RJ); Escola de Engenharia de Petrópolis (Petrópolis/RJ); Instituto de Ciência e Tecnologia (Rio das Ostras/RJ); Instituto do Noroeste Fluminense de Educação Superior (Santo Antônio de Pádua/RJ); Instituto de Ciências Humanas de Volta Redonda, a Escola de Engenharia Industrial e Metalúrgica e o Instituto de Ciências Exatas (Volta Redonda/RJ); Unidade Avançada José Veríssimo (Óbidos/PA). (Relatório de Autoavaliação Institucional 2019, ano base 2018 Parcial).
} 
se dá porque, para além do distanciamento físico das unidades do interior com relação à unidade central, tem-se o percurso administrativo emaranhado com decisões centralizadas na sede.

Entretanto, não é possível perceber como a política de estímulo à formação de "quase mercados", estipulada pela política da reforma de Estado tem afetado a universidade do ponto de vista organizacional. Este fenômeno, explica-se, em parte, pelo fato de as Universidades Públicas serem autarquias ${ }^{43}$, tendo autonomia didáticocientífica, administrativa e de gestão financeira ${ }^{44}$ e patrimonial (Constituição Federal de 1988, art. $n^{\circ}$ 207). Mas, trata-se de uma autonomia relativa, visto que, diferente de uma empresa pública, uma autarquia não pode estabelecer os seus próprios critérios de eficiência e de avaliação e, muito menos, aqueles relacionados à questão trabalho-vaga. Sendo entes autônomos e não possuindo total autonomia, as autarquias estão sob o controle e a administração da entidade que as criou (MEIRELLES, 2002, p. 325).

Assim, tanto a contratação tanto de servidores efetivos, quanto de terceirizados na Universidade Federal Fluminense, por exemplo, não são pensados de acordo com a relação interna estabelecida entre fins e meios, senão condicionada à política federal de contratação e a disponibilidade financeira - igualmente política - das universidades. Deste modo, a limitação para a realização de concursos públicos nas universidades, foi marcante durante o governo de Fernando Henrique Cardoso, enquanto no governo do Partido dos Trabalhadores, houve compensação de vagas docentes, ainda que tenha se detectado pouca mudança em relação aos técnico-administrativos ${ }^{45}$. A partir desse período, verifica-se um dos fenômenos que nos chama atenção: uso de terceirizados para funções administrativas ${ }^{46}$.

A força de trabalho da universidade compreende vários perfis. Relacionados ao tipo de vínculo profissional, encontramos: professor do magistério superior - Titular, Associado, Adjunto, Assistente, Adjunto A, Assistente A, Auxiliar; Técnico-

\footnotetext{
${ }^{43}$ Definida pelo Decreto-Lei no 200/1967 como "serviço autônomo, criado por lei, com personalidade jurídica, patrimônio e receita próprios, para executar atividades típicas da Administração Pública, que requeiram, para seu melhor funcionamento, gestão administrativa e financeira descentralizada".

${ }^{44}$ Diferentemente de uma empresa pública que estabelece os seus próprios critérios de eficiência.

${ }^{45}$ Mesmo durante os momentos de expansão.

${ }^{46}$ Diferentemente do servidor concursado que "mantém-se comprometido com as premissas que sustentam o aspecto burocrático do seu cargo" (CUERVO, 2013. p. 108).
} 
Administrativo em Educação - E, D, $\mathrm{C}^{47}$ e $\mathrm{B}^{48}$. Há, ainda, os professores substitutos ${ }^{49}$, servidores cedidos ${ }^{50}$ de outros órgãos, anistiados ${ }^{51}$ e prestadores de serviço terceirizados. Em certa medida, tal heterogeneidade acarreta tensões, visto que, num mesmo processo produtivo, atuam trabalhadores com diferentes vínculos empregatícios, estatutos, faixas salariais, prestígio e/ou status, direitos e carreira. Certamente, as tensões nos locais de trabalho são menores do que poderiam ser desde o ponto de vista das relações interpessoais. Mas as fragilidades são vividas a outra maneira.

Deste modo, por exemplo, as empresas que prestaram serviço terceirizado no Instituto de Ciências da Sociedade e Desenvolvimento Regional (ESR/UFF) em Campos dos Goytacazes, no ano de 2018, possuíam suas sedes administrativas nas regiões metropolitanas do Rio de Janeiro, o que dificultava o acesso as informações e esclarecimento de dúvidas dos trabalhadores que executavam suas atividades no interior do estado. Para sanarem estas dúvidas, não raro estes trabalhadores recorriam ao auxílio das chefias da unidade onde estavam atuando ${ }^{52}$.

Como a justificativa da terceirização na administração pública refere-se ao aumento da eficiência por meio da focalização em relação a uma atividade-fim, torna-se importante compreender como na Universidade Federal Fluminense isto se efetiva. Assim, como nas demais universidades públicas brasileiras, o uso de mão de obra terceirizada passou a ser uma fatia significativa dos trabalhadores da instituição. No caso da Universidade Federal Fluminense, no ano de 2006, cerca de mil e cinco trabalhadores eram contratados para a realização de atividades indiretas, enquanto no ano de 2008 esse número alcançava mil e sessenta e cinco ${ }^{53}$ postos, e entre $2017^{54}$ e $2019^{55}$, esse número

\footnotetext{
${ }^{47}$ Cargos em extinção.

${ }^{48}$ Cargos em extinção.

${ }^{49}$ Contratados em razão de vacância do cargo, afastamento ou licença ou para nomeação para ocupar cargo de direção de reitor, vice-reitor e direto de campus, conforme Lei $\mathrm{n}^{\mathbf{0}}$ 8.745/93.

${ }^{50}$ Lei 8.112/90 Art. 93.

${ }^{51}$ Lei no 8.878/94.

${ }^{52}$ A falta de comunicação e amparo por parte das empresas terceirizadas geram sentimento de descaso e desmotivação no trabalhador contratado, criando nesse grupo o sentimento de desconsideração, tanto pela empresa que a contratou e até mesmo pela UFF que muitas vezes não tem a resposta a perguntas importantes com respeito a salários, décimo terceiro salário, férias, FGTS, vale-transporte, reajustes salariais, acesso aos respectivos sindicatos, demissões, contratações, etc.

${ }^{53}$ Relatório de gestão da Universidade Federal Fluminense do ano de 2008, p.98.

${ }^{54}$ Os dados sobre o quantitativo de terceirizados (incluindo o hospital Universitário) não foram introduzidos nos relatórios do ano de 2017, mas podem ser conferidos no link: http://www.uff.br/?q=terceirizados

55 Dados obtidos por meio do relatório de autoavaliação institucional: UFF, (2020) - Relatório de Autoavaliação Institucional Parcial 2020 - Ano base 2019, p. 129.
} 
chegou a dois mil quatrocentos e sessenta e dois, e mil cento e dez trabalhadores terceirizados, respectivamente.

O crescimento ocorreu durante o período de expansão universitária, junto ao aumento das vagas discentes, do número de cursos e de professores, houve uma expansão das atividades diretas e indiretas, nem sempre atendidas por um número adequado de vagas de servidores efetivos da Universidade Federal Fluminense. Sendo assim, cresceu o número de trabalhadores envolvidos na limpeza, manutenção, segurança, jardinagem; mas, também, na recepção e na comunicação, onde, muitas vezes, telefonistas, acabavam desempenhando funções de atendentes de secretaria. Em vários casos, estas funções foram substituídas por técnico-administrativos concursados; mas, nem sempre as funções corresponderam ao número de vagas disponibilizadas nos concursos.

Com o fim da expansão, a partir de 2014, o número de terceirizados independentemente das funções realizadas - vem sofrendo cortes significativos, o que tem se acentuado a partir de 2018 e, principalmente, no ano de 2019, na Universidade Federal Fluminense, em função dos cortes (cerca de $30 \%$ das verbas discricionárias ${ }^{56}$ das Universidades Federais) e dos bloqueios orçamentários efetuados pelo Ministério da Educação, impactando diretamente nos contratos firmados pela universidade.

Paralelemente, em 2019, a instituição implementou o sistema de ponto eletrônico biométrico para os servidores e a jornada de trabalho de 40 horas para os servidores técnico-administrativos, depois de terem adotado uma carga horária semanal de 30 horas a partir da década de $1980^{57}$. Simultaneamente, foram demitidos, praticamente, todo o

\footnotetext{
${ }^{56} \mathrm{O}$ Ministério da educação considerou como verbas discricionárias os "recursos que são geridos pelas universidades no âmbito de sua autonomia administrativa, efetuando gastos com funcionamento, obras, contratação de serviços de terceirização de mão de obra e despesas com assistência estudantil" http://portal.mec.gov.br/component/tags/tag/50211.

${ }^{57}$ Ainda no ano de 2019, a UFF implementou o sistema de ponto eletrônico biométrico para os servidores Técnico-administrativos, baseado numa decisão judicial expedida pela $4^{\text {a }}$ Vara de Niterói transitada em julgado. Além da implementação do ponto eletrônico, o qual ainda gera grande desconforto e embates entre os servidores e a reitoria, o cumprimento da jornada de trabalho de 40 horas para os servidores técnicoadministrativos também ocasiona sérias tensões, em vista do cumprimento das normas e dos critérios de flexibilização publicados pela Reitoria. Isso porque, há mais de três décadas os servidores da UFF trabalham 30 horas semanais, tendo em vista a autonomia universitária, num sistema de atendimento ininterrupto de 12 horas diárias de trabalho, conforme previsto no Decreto n ${ }^{\circ} 1590$ de 10/08/1995. Não iremos nos ater as questões legais e morais que envolvem os fatos apresentados, o objetivo de trazer esse cenário à tona é dar luz a detalhes que no nosso entendimento, são conexos. Afinal, a implementação do ponto eletrônico, o cumprimento da jornada de 40 horas e a dificuldade em atender aos critérios para a flexibilização contribuíram para a demissão de muitos funcionários terceirizados que trabalhavam nos setores administrativos na UFF no ano de 2019. Restando, desse modo, os contratos relacionados às atividades-meio, que são os serviços de limpeza, manutenção predial, vigilância, vigia, recepção e algumas atividades na área da tecnologia da informação.
} 
quadro de funcionários terceirizados que trabalhavam nos setores administrativos na UFF no ano de 2019, dos 406 postos de trabalho terceirizados para apoio operacional administrativo que a UFF detinha no ano de 2018 restaram 26 postos no ano de $2019^{58}$. Permanecendo, desse modo, os contratos relacionados as atividades-meio, que são os serviços de limpeza, manutenção predial, vigilância, vigia, recepção e algumas atividades na área da tecnologia da informação, alcançando o quantitativo de 1110 trabalhadores, cerca de $8 \%$ a mais do número de pessoal terceirizado em 2007, ano imediatamente anterior à implementação do Programa de Expansão Universitária (REUNI), programa este que ampliou o número de vagas discentes e de cursos na $\mathrm{UFF}^{59}$.

De 2018 a 2022, a UFF fixou a meta de reduzir o número de funcionários terceirizados e implementar o redimensionamento da força de trabalho ${ }^{60}$.

\section{Tabela 1 - Objetivos, Indicadores e Metas de Desempenho da Perspectiva de Gestão de Pessoas}

\begin{tabular}{|l|l|c|c|c|c|c|}
\hline \multicolumn{1}{|c|}{ Objetivo Estratégico } & \multicolumn{1}{|c|}{ Indicador de redução no número de } & 2018 & 2019 & 2020 & 2021 & 2022 \\
\hline \multirow{2}{*}{$\begin{array}{l}\text { 1 Redimensionar e } \\
\text { capacitar a força de } \\
\text { trabalho }\end{array}$} & $\begin{array}{l}(\%) \text { de } \\
\text { funcionários terceirizados na área } \\
\text { administrativa }\end{array}$ & $\begin{array}{l}\text { \% de metas alcançadas no plano de } \\
\text { distribuição de vagas }\end{array}$ & $\begin{array}{l}\text { Implantação do plano de distribuição } \\
\text { de vagas até o final da vigência do } \\
\text { PDI }\end{array}$ \\
\hline
\end{tabular}

Fonte: UFF, (2020) - Relatório de Autoavaliação Institucional Parcial 2020 - Ano base 2019.

Entre as medidas tomadas, inclui-se, ainda, a promoção da remoção interna, programa de capacitação e elaboração e implementação do plano de redistribuição das vagas de docentes e técnicos, geradas por aposentadoria-exoneração-falecimento. O corte de orçamento e a recusa ao provimento de novas vagas, por parte do governo federal estimulam ao 'enxugamento da organização'. Contudo, os enxugamentos parecem ser a única e estratégia para a gestão.

Nessa perspectiva, tal análise reforça a autonomia relativa da universidade frente a sua real necessidade. Os números apontam o disparate em relação à demanda apresentada pela universidade em um período de expansão como o REUNI e as definições

\footnotetext{
${ }^{58}$ Relatório de autoavaliação institucional da UFF 2020. Ano base 2019, p. 129.

${ }^{59}$ No ano de 2007 a UFF contava com cerca de 70 cursos de graduação, já em 2019, após a implementação do REUNI tal número alcançou a marca de 131 cursos de graduação.

${ }^{60}$ Conforme proposto pelo TCU em 2018 o dimensionamento da força de trabalho é realizado "com cálculo do quantitativo de servidores, de modo a mensurar a necessidade real dos órgãos” (TCU, 2018). A UFF utiliza o termo redimensionamento para especificar uma nova rodada da aplicação da metodologia, com uma reorganização da estrutura.
} 
e planejamento de vagas adotadas pelo alto escalão do governo. Não acreditamos que a terceirização na universidade venha a se esgotar, muito pelo contrário, a tendência é de aumento frente a constante flexibilização das normas e a extinção de cargos efetivos. Nessa perspectiva, os fatos trazidos anteriormente são resultado de uma conjuntura de transição política numa esfera federal e também local, após adoção de medidas econômicas liberais por parte do governo atual bem como da política adotada pela atual gestão universitária.

\section{CONCLUSÕES}

Interpretar a terceirização na administração pública brasileira exige que se tome certa distância dos debates habituais em torno do tema, evitando tomar o modelo pelos fatos ou alinhar-se a priori em torno de duas abordagens opostas: a que toma a terceirização como um aspecto virtuoso da gestão produtiva contemporânea; e a que a toma como uma mera estratégia de flexibilização/precarização do trabalho. Igual predomínio dos modelos parece ocorrer ao considerar a administração pública no caso da reforma do Estado dos anos 90.

A terceirização como elemento gerencial, pode ser pensada como um componente de aumento da eficiência da organização estatal, promovida segundo os critérios das empresas contemporâneas, nas quais a focalização e a flexibilidade são componentes centrais. Se nas empresas, sabe-se bem, que a relação meios e fins regula-se pelos mercados, no âmbito estatal está regulação ocorre politicamente. Nese sentido, o caso da Universidade Federal Fluminense, constitui uma oportunidade de pensar esta relação. Gostaríamos de indagar: até que ponto os elementos da administração gerencial propostos por Bresser Pereira foram exitosos? Qual seria o grau de eficácia e o alcance das mudanças? Como se definem os fins e os critérios de avaliação dos empreendimentos púbicos? Não pretendemos responder aqui todas as questões senão formula-las melhor, reunir dados e indícios para chamar a atenção sobre a força retórica da Reforma do Estado em relação à terceirização.

Para começar, seria preciso afirmar que a terceirização é um elemento presente na organização do Estado há muito tempo. Se bem, a administração pública organiza-se a partir dos anos 1930 segundo um critério racional-legal e as empresas públicas desempenharam um papel central no desenvolvimento do capitalismo industrial 
brasileiro. Esse padrão é questionado há décadas, desse modo, os processos de contratação e formação de empresas e empreendimentos públicos tenham sido: talvez, menos planejados e mais aleatórios do que habitualmente se pensa. Nesse sentido, o modelo da gestão gerencial afirma a prevalência dos critérios políticos que definem as atividades fins do Estado e do modo em que devem ser prestadas.

Ao tratar das Universidades Públicas, o sucesso da focalização não pode ser medido pela incidência da terceirização, mas sim pelo modo, como a definição de seus fins e meios incide sobre sua organização. Assim, o modelo da Reforma do Estado nas universidades, organizou-se como "quase mercados", capazes de incentivar a competitividade e a otimização de esforços. As políticas que as estimularam foram várias e mutáveis no tempo: a gestão das vagas efetivas, extinção de cargos públicos, fiscalização de órgão de controle (TCU, CGU), políticas de graduação, de pós-graduação e pesquisa, além da política orçamentária.

Em termos de vagas funcionais, até 2002, houve retração e igualmente desestímulo ao ensino público e incentivo ao ensino privado. Entre 2003 e 2014, houve uma grande expansão de vagas, associada à expansão universitária, com escasso vínculo com a organização real e objetivos da produção de serviços.

Assim, tanto a contratação tanto de servidores efetivos, quanto de terceirizados na UFF não são pensados de acordo com a relação interna, estabelecida entre fins e meios, senão condicionada à política federal de contratação e a disponibilidade financeira igualmente política - das universidades. Assim, verifica-se um fenômeno que chama a atenção: o uso frequente de terceirizados para funções administrativas.

\section{REFERÊNCIAS}

ANTUNES JÚNIOR, J. A. V.; KLIEMANN NETO, F. J.; FENSTERSEIFER, J. E. Considerações críticas sobre a evolução das filosofias de administração da produção: do "just-in case" ao "just-in-time". Revista de Administração de Empresas, v. 29, n. 3. Revista da Administração. São Paulo, 1989.

ANTUNES, Ricardo. Adeus ao trabalho? Ensaio sobre as metamorfoses e a centralidade do mundo do trabalho. São Paulo: Cortez, 2002.

ANTUNES, R. (Org.). Riqueza e miséria do trabalho. São Paulo: Boitempo, v. II. 2013.

BRASIL. Constituição dos Estados Unidos do Brasil, de 10 de novembro de 1937. Diário 
Oficial da União: seção 1, p. 22.359, 10 nov. 1937.

BANDEIRA DE MELLO, Celso Antônio. Curso de Direito Administrativo. São Paulo: Malheiros, p. 154-155, 1996.

BRASIL. Decreto ${ }^{\circ} 1.713$, de 28 de outubro de 1939. Dispõe sobre o Estatuto dos Funcionários Públicos Civis da União. Diário Oficial da União: seção 1, p. 0, 01 nov. 1939.

BRASIL. Decreto n ${ }^{\circ} 5.936$ de 28 de outubro de 1943. Consagra ao Servidor Público o dia 28 de outubro. Diário Oficial da União: seção 1, p. 15.988, 28 out. 1943.

BRASIL. Lei $n^{\circ} 3.848$, de 18 de dezembro de 1960. Cria a Universidade do Estado do Rio de Janeiro, e dá outras providências. Diário Oficial da União: seção 1, p. 16118, 20 dez. 1960.

BRASIL. Decreto $n^{\circ}$ 200, de 25 de fevereiro de 1967. Dispõe sobre a organização da Administração Federal, estabelece diretrizes para a Reforma Administrativa e dá outras providências. Diário Oficial da União: seção 1, suplemento p. 4, 27 fev. 1967.

BRASIL. Lei $\mathrm{n}^{\circ} 5.645$ de 10 de dezembro de 1970. Estabelece diretrizes para a classificação de cargos do Serviço Civil da União e das autarquias federais, e dá outras providências. Diário Oficial da União: seção 1, p. 10.537, 11 dez. 1970.

BRASIL. Lei n 6019 de 03 de janeiro de 1974. Dispõe sobre o Trabalho Temporário nas Empresas Urbanas, e dá outras Providências. Diário Oficial da União: seção 1, p. 73, 04 jan. 1974.

BRASIL. Constituição de 1988. Constituição da República Federativa do Brasil. Diário Oficial da União: seção 1, p. 1, 5 out. 1988.

BRASIL. Lei no 8666 de 21 de junho de 1993. Regulamenta o art. 37, inciso XXI, da Constituição Federal, institui normas para licitações e contratos da Administração Pública e dá outras providências. Diário Oficial da União: seção 1, p. 8.269, 22 jun. 1993.

BRASIL. Tribunal Superior do Trabalho. Súmula no 331, de 21 de dezembro de 1993. Locação de mão-de-obra. Terceirização. Contrato de prestação de serviços. Legalidade. Responsabilidade subsidiária do tomador de serviço. Diário da Justiça da república Federativa do Brasil: seção 1, p. 28.358, DF, 21 dez. 1993.

BRASIL. Decreto n 2271 de 07 de julho de 1997. Dispõe sobre a contratação de serviços pela Administração Pública Federal, autárquica e funcional e dá outras providências. Diário Oficial da União: seção 1, p. 14.293, 8 jul. 1997. Revogado pelo decreto $n^{\circ} 9.507$ de 21 det. 2018.

BRASIL. Emenda Constitucional no 19 de 04 de junho de 1998. Modifica o regime e dispõe sobre princípio e normas da Administração Pública, Servidores e Agentes políticos, controle de despesas e finanças públicas e custeio de atividades a cargo do Distrito Federal, e dá outras providências. Diário Oficial da União: seção 1, eletrônico p.1, 5 jun. 1998.

BRASIL. Tribunal de Contas da União. Relatório de levantamento - TC 022.577/20122. Levantamento de governança e gestão de pessoas na Administração Pública Federal, 1 jan. 2013.

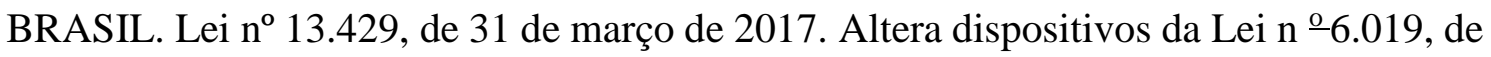


3 de janeiro de 1974, que dispõe sobre o trabalho temporário nas empresas urbanas e dá outras providências; e dispõe sobre as relações de trabalho na empresa de prestação de serviços a terceiros. Diário Oficial da União: seção 1, edição extra p.1, 31 mar. 2017.

BRASIL. Lei $n^{\circ} 13.467$ de 13 de julho de 2017. Altera a Consolidação das Leis do Trabalho (CLT), aprovada pelo Decreto-Lei $\mathrm{n}^{\circ} 5.452$, de $1^{\circ}$ de maio de 1943 , e as Leis n ${ }^{\circ} 6.019$, de 3 de janeiro de 1974, 8.036, de 11 de maio de 1990, e 8.212, de 24 de julho de 1991, a fim de adequar a legislação às novas relações de trabalho. Diário Oficial da União: seção 1, p. 1, 14 jul. 2017.

BRASIL. Decreto ${ }^{\circ} 9.507$ de 21 de setembro de 2018. Dispõe sobre a execução indireta, mediante contratação, de serviços da administração pública federal direta, autárquica e fundacional e das empresas públicas e das sociedades de economia mista controladas pela União. Diário Oficial da União: seção 1, p. 3-4, 24 set. 2018.

BRASIL. Ministério da Educação. MEC libera 100\% dos recursos para instituições federais do país. Assessoria de Comunicação Social. Brasília: MEC, 2018. Disponível em: http://portal.mec.gov.br/component/tags/tag/50211. Acesso em: 23 jun. 2020.

BRASIL. Tribunal de Contas da União. Projeto Dimensionamento da Força de Trabalho. Secretaria de Gestão de Pessoas - Ministério do Planejamento, Desenvolvimento e Gestão, 2018.

BRASIL. Decreto $n^{\circ} 10.183$ de 20 de dezembro de 2019. Altera o Decreto $n^{\circ} 9.507$, de 21 de setembro de 2018, que dispõe sobre a execução indireta, mediante contratação, de serviços da administração pública federal direta, autárquica e fundacional e das empresas públicas e das sociedades de economia mista controladas pela União. Diário Oficial da União: seção 1, edição extra B, p. 120 dez. 2019.

BRESSER-PEREIRA, L. C. Da administração pública burocrática à Gerencial. Revista do serviço Público, 1996. Disponível em: http://www.bresserpereira.org.br/papers/1996/95.admpublicaburocraticaagerencial.pdf. Acesso em: 24 mar. 2019.

BRESSER-PEREIRA, L. C. Reforma do Estado nos anos 90: lógica e mecanismos de controle. Brasília: MARE, Cadernos MARE, n. 1, 1998. Disponível em: http://www.scielo.br/pdf/ln/n45/a04n45.pdf. Acesso em: 24 mar. 2019.

CASTRO, Nadya Araújo. Modernização e trabalho no complexo automotivo brasileiro: reestruturação industrial ou japanização de ocasião? Novos Estudos Cebrap, São Paulo, n.37, p.155-74 nov. 1993.

CORIAT, B. Pensar pelo avesso: o modelo japonês de trabalho e organização. RJ. Editora da UFRJ/Reavan, 1994.

CORTE, Andréa Tello da; MARTINS, Ismênia de Lima. 50 anos da Universidade Federal Fluminense - 1960-2010. Niterói-RJ: Editora da UFF, 2010.

CUERVO, Gabriela de lima. Carreiras profissionais, carreiras políticas: um estudo sobre a relação entre emprego público e política municipal. Dissertação Mestrado em Sociologia - UFF. 2013.

DRUCK, Maria da Graça; SENA, Jeovana; PINTO, Marina; ARAÚJO, Sâmia. A terceirização no serviço público: particularidades e implicações. Organizador: André Gambier Campos. - Brasília: Ipea, 2018. Disponível em: 
http://repositorio.ipea.gov.br/bitstream/11058/8258/1/Terceirização\%20do\%20trabalho $\% 20$ no\%20Brasil_novas $\% 20 \mathrm{e} \% 20$ distintas\%20perspectivas $\% 20$ para\%20o\%20debate.p df. Acesso em: 20 mar. 2019.

DRUCK, Graça; DUTRA, Renata and SILVA, Selma Cristina. A CONTRARREFORMA NEOLIBERAL E A TERCEIRIZAÇÃO: a precarização como regra. Cad. $C R H$ [online]. 2019, vol.32, n.86, pp.289-306. Epub Oct 10, 2019. ISSN 1983-8239. Disponível em: https://doi.org/10.9771/ccrh.v32i86.30518. Acesso em: 12 fev. 2020.

FONTAINHA, Fernando de Castro. et al. Processos seletivos para a contratação de servidores públicos Brasil, o país dos concursos? Fundação Getúlio Vargas Direito Rio, 2014, p. 117.

HARVEY, David. Condição Pós-Moderna. Uma pesquisa sobre as origens da mudança cultural. Edições Loyola, São Paulo, Brasil, 1989, P. 135-162.

MARCELINO, Paula Regina Pereira. Afinal, o que é terceirização? Em busca de ferramentas de análise e de ação política. Pegada, vol. 8. n. 2, dez. 2007. Disponível em: https://revista.fct.unesp.br/index.php/pegada/article/viewFile/1640/1570. Acesso em: 12 jan. 2019.

MARCELINO, P.; CAVALCANTE, S. Por uma definição de terceirização. Caderno CRH, Salvador v. 25, n. 65, p. 331-346, 2012. Disponível em: http://www.scielo.br/scielo.php?pid=S0103-

49792012000200010\&script=sci_abstract\&tlng=pt. Acesso em: 25 fev. 2019.

MEIRELLES, Hely Lopes. Direito Administrativo Brasileiro. $28^{\circ}$ ed. São Paulo, p.333, 2003.

PIORE, M. J. \& SABEL, C. F. The second industrial divide: possibilities for prosperity. New York : Basic Books, 1984.

PIORE, M e SABEL, C. Les chemins de la prosperité, de la production de masse à la spécialisation souple.Tradução livre.Paris: Hachette, 1989.

SILVA, Rafael. Reportagem Especial: Responsabilidade solidária e subsidiária com Eduardo Frade. TST. Publicado em 20/02/2018. Disponível em http://www.tst.jus.br/radio-destaques/-/asset_publisher/2bsB/content/reportagem-

especial-responsabilidade-solidaria-e-subsidiaria?inheritRedirect=false . Acesso em: 18 de jul. de 2020.

SOUZA, S. Z. L., OLIVEIRA, R. P. Políticas De Avaliação Da Educação E Quase Mercado No Brasil. Educ. Soc., Campinas, vol. 24, n. 84, p. 873-895, set. 2003.

UNIVERSIDADE FEDERAL FLUMINENSE. Estatuto e Regimento Geral. Diário Oficial da União: seção 1, 5 maio 1983.

UNIVERSIDADE FEDERAL FLUMINENSE. Relatório de gestão 2006. Niterói, RJ: 2007.

UNIVERSIDADE FEDERAL FLUMINENSE. Relatório de gestão 2008. Niterói, RJ: 2009.

UNIVERSIDADE FEDERAL FLUMINENSE. Contratos UFF - 2008 a 2020. Disponível

em: 
http://www.uff.br/?q=contratos\&field_exercicio_ano_contrato_value=2018\&title=\&fiel d_empresa_contrato_value $=\&$ body_value $=$ Acesso em: $12 \mathrm{fev} .2020$.

UNIVERSIDADE FEDERAL FLUMINENSE. Relatório de gestão 2009. Niterói, RJ: 2010 .

UNIVERSIDADE FEDERAL FLUMINENSE. Relatório de gestão 2017. Niterói, RJ: 2018.

UNIVERSIDADE FEDERAL FLUMINENSE. Relatório de gestão 2018. Niterói, RJ: 2019.

UNIVERSIDADE FEDERAL FLUMINENSE. Relatório de autoavaliação institucional 2018. Ano base 2015, 2016 e 2017. Niterói, RJ: 2018.

UNIVERSIDADE FEDERAL FLUMINENSE. Relatório de Autoavalização Institucional 2019 - Ano base 2018 Parcial. 2019. Niterói, RJ: 2020.

WEBER, M. Economia e Sociedade: fundamentos da sociologia compreensiva/ Max Weber; trad. de Regis Barbosa e Karen Elsabe Barbosa; ver. Téc. De Gabriel Cohn, $4^{\mathrm{a}}$ ed. $4^{\mathrm{a}}$ reimpressão - Brasília: Editora Universidade de Brasília, v.1, 2015. 